\title{
La Tutela del Cliente Bancario Desde la Ley de Defensa del Consumidor en el Derecho Argentino
}

\author{
Eduarda eA. Hartiex
}

Professor de Direito Civil e Comercial da Faculdade de Direito da Universidade de Buenos Aires, Argentina

\begin{tabular}{|c|}
\hline \multicolumn{1}{c|}{ Sumário } \\
1. La necesidad tuitiva del cliente ban- \\
cario y la Ley de Protección del Consumi- \\
dor. \\
2. Elementos para una teoría restricti- \\
va. \\
3. La hipótesis expansiva. \\
4. Consecuencias de la aplicación de la \\
leyal cliente bancario. \\
5. Conclusión.
\end{tabular}

\section{La Necesidad Tuitiva del Cliente Bancario y la Ley de Protección del Consumidor:}

1 cliente bancario general o usuario bancario como expresión de uno de los mercados de la actividad financiera, padece al igual que el consumidor general de un inferioridad relativa frente al cocontratante.

De igual modo, como sucede en las relaciones de consumo general, la predisposición, la estandarizaciòn y las condiciones generales aparecen complacientemente justificadas por la necesidad de dinamizar los negocios y facilitar el acceso general.

Luego en la especie bancaria la escasez de la disciplina contractual que aporta el ordenamiento de fondo y las leyes que regulan la actividad han favorecido la idea de un derecho especial, generando un am-

Trabalho apresentado no curso organizado pelo Mestrado em direito da UFRGS, I Jornada sobre dano à pessoa e ao consumidor no direito Brasileiro e Argentino, 02 e 03 de junho de 1997. 
plio espacio para las condiciones generales, la práctica y los usos bancarios.

to legal ofrece, obligándonos al mismo tiempo a propugnar su perfectibilidad.

La disciplina contractual bancaria está en mayor medida elaborada por la propia banca, favorecida además por la influencia que ejerce la idea de "recolección del ahorro" y la exigencia particular de protección de la empresa bancaria, bajo el perfil de "contención o reducción del riesgo".

De la conjunción de estas circunstancias puede coincidirse -al igual que frente al consumidor general- en la necesidad de una intervención del legislador para tutelar adecuadamente al cliente bancario.

Dicho esto conviene recordar que rige hoy en la Argentina la Ley de Protección del Consumidor ${ }^{1}$, y aún no se ha concluido categóricamente que sus disposiciones puedan aplicarse libremente al cliente bancario.

En efecto, ardua tarea resulta expedirse sobre la compatibilizaciòn de las dos circunstancias descriptas: necesidad de tutelar adecuadamente al cliente bancario y la existencia de una Ley de Protección del Consumidor; a modo de introducción conviene desde ya anticipar que las posiciones relativas a tal posibilidad no son concluyentes ni tienden tampoco a excluirse; así quienes estarían en posición de cuestionar la aplicabilidad de la ley 24240 "al consumidor bancario" no podrían dejar de reconocer que ciertos aspectos de la actividad bancaria están alcanzados por la norma, en tanto quienes pretendiésemos refugiar al cliente bajo la protección de la ley no podríamos ignorar las dificultades que el tex-

\section{Fundamentos para una Teoría Restrictiva:}

El cliente bancario singular, aún considerando como tal a aquel merecedor de una tutela especifica, no ha sido identificado plenamente con el consumidor, y ello como derivación lógica que a estos los define. (además de su posición subjetiva) "el acto de consumo"; luego la relación desde el punto de vista objetivo en uno y otro ámbito son marcadamente distintos, aunque guardan cierta identidad cuando la prestaciòn financiera no tiene una vinculación directa con el ejercicio del crédito, léase la prestación de servicios, en cuyo caso la compatibilización es posible accediendo a la caracterización de "usuario".

En efecto el acto o relación de consumo pensado para calificar al consumidor responde en lo sustancial a la adquisición de bienes y la obtención de servicios, de consumo o de uso.

Ciertamente el acto que verifica la relación entre banco y cliente si bien no diametralmente opuesto a la actividad con tutela legal específica, evidencia una diversidad que no es menor ya que la relación de consumo que tutela la ley de defensa del consumidor se refiere a los bienes de consumo o de uso, adquiridos por el destinatario final para su uso propio, el de su familia o de su grupo social (Cfe. Art. 2 Ley 24.240).

Dicho de otro modo al consumidor lo define una posición determinada por:

\footnotetext{
1. Ley 24240, Sanc 22.09.93; Promulgación Parcial 13.10.93.BO 15.10.93
}

a) aspectos positivos; así se consideran consumidores o usuarios, las personas físicas o jurídicas que contratan a título oneroso para su consumo final o beneficio propio o de su grupo familiar o social (cfe. Art. $1^{\circ}$ ),

b) aspectos negativos; en tanto se excluyen de tal carácter a quienes adquirieran, almanecen, utilicen o consuman bienes o servicios para integrarlos en procesos de producción, transformación o comercialización o prestación a terceros (Cfe. Art. $2^{\circ}$ )

Con esos parámetros fijados por el legislador podría pensarse que el crédito y el dinero que constituyen el objeto de la intermediaciòn, que a su vez califica la actividad bancaria, están excluidos de aquella enunciación de consumo, en tanto estos representan una promesa de pago diferido, implicando cambio de bienes actuales por bienes futuros, ocasionando una circulación de mercaderías o valores, o aun la permuta de la misma cosa en momentos diferentes, un intercambio diferido en el tiempo o aún, una inserción del tiempo en el cambioº

Conforme tal temperamento se ha señalado v.g. que la Ley de Protección al Consumidor Brasileña (№ 8078) no se aplica a las operaciones de producción, ahorro e inversión, o sea, a la captación de recursos por las instituciones financieras, bajo cualquier forma, tampoco se aplica a las operaciones de prestamos y otras análogas realizadas por los bancos, pues el dinero y

el crédito no constituyen productos adquiridos o usados por el destinatario final, siendo, al contrario, instrumentos o medios de pago que circulan en la sociedad y en relación a los cuales no hay destinatario final ${ }^{3}$.

Siguiendo esta línea argumental se ha señalado que respecto de nuestra Ley 24.240 el punto liminar para determinar su aplicación a la actividad bancaria debe ser la consideración de la naturaleza jurídica del dinero, a la postre objeto del contrato de mutuo, piedra angular de la negociación bancaria, luego en ese entendimiento habiéndose negado el concepto de cosa al dinero para asignarle la identidad esencial de una unidad de cambio o de medida del ámbito patrimonial, resultaría que la ley sólo es aplicable a las entidades financieras en tanto y en cuanto éstas desarrollan actividades de servicios, quedando excluido de esta operatoria el negocio tradicional del mutuo 4 .

Tal distinción daría fundamento para bloquear la posibilidad de extender en buena medida al cliente bancario el estatuto del consumidor, quedando de tal modo expuesto a los sinsabores de una relación desigual y de consecuencias igualmente disvaliosas.

Ciertamente el criterio restrictivo parece encontrar entre nosotros fundamento suficiente en la Ley 24.240 que extiende sus efectos a los supuestos de financiación concedida por los proveedores no financieros de bienes y servicios, y tal vez sin

Revista da Faculdade de Direito da UFRGS, v. 13, 1997

2. Wald, A. El Derecho del Consumidor y sus Repercusiones en Relación con las Instituciones Financieras-Pag.574

3. Wald, A. El Derecho del Consumidor y su Repercusiones en Reación con las Instituciones Financieras -Pag.574

4. Benlbaz, A. y Coll, O - Sisitema Bancario Moderno, Depalma Ed 1994, To II, Pag.528.

Revista da Faculdade de Pirkite da UFRGS, v. 13, 1997

FACULDADE DE DIREITO

BIBLIOTECA 
proponèrselo excluye de su ámbito al crédito bancario o al de otros intermediarios financieros institucionales ya que el segundo párrafo del artículo 36 establece que el BCRA adoptará las medidas conducentes para que las entidades sometidas a su jurisdicción cumplan, en las operaciones de crédito para consumo, con lo indicado en esta ley, remisión que aporta confusión bastante ya que bien podría pensarse que el legislador no ha tenido a los bancos como partícipes de una actividad comprendida en la norma $\mathrm{a}^{5} \mathrm{o}$ tenièndolos por tales delego su tratamiento a la autoridad financiera, pero además siempre pensando sólo en una especie del crédito - el destinado a la adquisición de bienes y servicios.

De tal forma siempre parece notoria la exclusión del crédito bancario cuando no está destinado a la adquisición de cosas o servicios, no obstante tal enunciación encierra como dato de mayor interés que el "crédito" como operación económica no está excluída del acto de consumo.

En efecto el párrafo $1^{\circ}$ del Art. 36 de la ley citada establece bajo el confuso título "de las operaciones de venta de crédito" los requisitos exigidos cuando se trate de operaciones de crédito para la adquisición de cosas o servicios; de donde las operaciones de crédito extrañas a tales fines o, no enunciadas suficientemente, esto es en aquellos donde no se señala cual será el destino del préstamo, permanecen al margen de la previsión legal.

Se verificaría siguiendo esta interpretación que las operaciones de "crédito ban-

5. Benelbaz, A. y Coll, O - Sistema Bancario Moderno, Depalma Ed 1994, $T^{2} \|$ II, Pag.527.

6. Micele, M. La Ley de Protección al Consumidor - Revista La Ley 09.03.94. cario" al consumo permanecen fuera de la órbita diseñada para tutelar al consumidor genérico, por una doble vía: a) por la diversidad que evidencia el objeto de la relación de consumo en el mercado de la comercialización de cosas y servicios respecto del objeto de la relación de consumo en el ámbito financiero; b) de igual modo, cuando el legislador recomienda al BCRA extender las exigencias de la ley al mercado financiero cuando este otorgue crédito para el consumo, dando a entender que sin tal intervención los clientes no están alcanzados por los efectos de la Ley de Protección del Consumidor.

Por lo demás no falta la posición de quien puntualiza que la ley se refiere a una sola (la bancaria) de las tres formas de operar las operaciones de venta a crédito: la ofrecida por el vendedor, los sistemas de ahorro para fines determinados y los créditos individuales o familiares otorgados por las instituciones bancarias; circunstancia que además parece ignorar que la institución bancaria al otorgar un crédito para fines de consumo, no está vinculado con las adquisiciones de bienes ni con las prestaciones de servicios que contrató el solicitante ${ }^{6}$.

Tal observación reafirma que la extensión de la ley de protección al consumidor al mercado bancario podría desde cierto sector juzgàrselo inalcanzable, porque los bancos son en principio extraños a la relación de consumo.

La pretensión expansiva del estatuto del consumidor para tutelar las relacio- nes del usuario bancario encontraría aún dificultades si quisiera ser superada la restricción apelando al debate legislativo y a la sanción definitiva de la ley 24.240 que modifica el título de las "operaciones de venta a crédito" por un nuevo e inverosímil encabezamiento de "operaciones de venta a crédito", aunque la intención haya sido alcanzar las operaciones de préstamo según ilustra el debate parlamentario?

Ahora bien, si por vía de hipótesis se admitiese que la Entidad Fiscalizadora de la actividad bancaria adoptase la recomen dación del Art. 36 de la Ley 24.240, de igual modo encontraríamos otras dificultades ya que los efectos tutelares se extenderían sólo a una manifestación bancaria: el crédito para el consumo (el art. 36 no fue reglamen tado por el DEC. 1798/94); luego con algún esfuerzo podríamos afirmar que otras manifestaciones de la actividad bancaria como lo son las prestaciones de servicios no vin culadas al crédito podrían quedar alcanzados por la ley del consumidor de acuerdo a la formulaciòn genérica del citado Art. 1으.

Con todo, los márgenes de las exclusiones no son menores sino piénsese v.g. en los créditos hipotecarios para la adquisición de inmuebles usados, en las operaciones de depósito, en las transferencias electrónicas de fondos cuando contienen alguna forma de crédito extraña a una operaciòn de consumo, entre otros muchos.

Luego con la exclusión se desaprovecha la posibilidad de extender al merca do bancario del cliente general las ventajas que confiere una normativa tutelar.
Con lo dicho puede delinearse el siguiente cuadro actual de situación: existencia de una ley general de protección del consumidor, posibilidad insuficiente de extender los beneficios de la tutela a un área restringida de las prestaciones bancarias, y la aparente convicción de suficiencia de la tutela general.

Sintetizando hay al menos dos aspectos que parecen dar razón a quienes podrían alentar la exclusión del cliente bancario de la tutela prevista en la Ley 24.240: uno sustancial -relativo al objeto de las operaciones de crédito - y otro formal - el modo y los alcances con que se ha incorporado la tutela del crédito al consumo.

\section{La Hipótesis Expansiva:}

La Ley de Protección al Consumidor atiende en alguna medida la necesidad apuntada de implementar una red de contención frente a los comportamientos avasallantes de los empresarios ya que disciplinó, junto a la relaciòn de consumo comprensiva de los servicios-, la relación del crédito al consumo.

En efecto quienes presten "servicios" de cualquier naturaleza están obligados a respetar los términos, plazos, condiciones, modalidades, reservas y demás circunstancias conforme a las cuales hayan sido ofrecidos, publicitados o convenidos (Cfe. Art. 19).

En las "operaciones de crédito" para la adquisición de cosas o servicios deberán consignarse bajo pena de nulidad las modalidades de ejecución (Cfe. Art. 36).

7. Antecedentes Parlamentarios Revista La Ley Año 1994, № 1, Pag.98. 
Siguiendo tales enunciaciones legales la contratación bancaria que gira sustancialmente en torno a la intermediaciòn entre la oferta y la demanda de dinero, en el ejercicio del crédito y en la prestación de servicios, parece en líneas generales disciplinada por la ley de protección al consumidor; tal apreciación se confirma atendiendo a los elementos subjetivo y objetivo de la relación de consumo.

Atendiendo al concepto de "proveedor" si bien la ley 24.240 no hace mención expresa a las entidades bancarias (salvo en lo referente a los créditos para consumo), ha de considerarse que estas se encuentran alcanzadas, ya que se trata de aquellas personas jurídicas a que se refiere el Art. 2 o que "en forma profesional prestan servicios a consumidores o usuarios", no tratándose de los servicios expresamente excluidos ${ }^{8}$.

El otro término de la relación - "el consumidor" - aparece caracterizado en el Art. $1^{\circ}$ al decir que es necesario que el negocio quede concluido por personas físicas o jurídicas que contratan a titulo oneroso para su beneficio, ò el de su grupo familiar o social, la adquisición o locación de cosas de muebles, la prestación de servicios, la adquisición de inmuebles nuevos destinados a vivienda, incluso los lotes de terreno con el mismo fin, cuando la oferta sea pública y dirigida a personas indeterminada.

8. Vazquez Ferreyra, R. y Romero O. - Revista La Ley 14.06.96, Pág.1.

9. Bergel, S. y Paolantonio M. - Anotaciones sobre la Ley de Defensa del Consumidor. Pág.496, Revista El Derecho To 155.

10. Callaiz, Aulloy, J.- Droit de la Consonmation, $3^{\circ}$ ED - Dalloz, París, Pág.4. Cit. por Bergel Paolantonio en Anotacines sobre la Ley de Defensa del Consumidor. Pag.496, Ed. Revista El Derecho 155.

11. Schmukler de Dozoretz, E. c/Banco Mercantil Argentino SA s/Daños y Perjuicios - C.Clvil Sala 12, 21.3.96 JA.
Fuera de ello para la ley no tendrán el carácter de consumidores o usuarios, quienes adquieran, utilicen o consuman bienes para integrarlos a procesos de transformación, comercialización o prestación a terceros (Cfe. Art. 2o, 2do. Párrafo).

Así partiendo de las distinciones clásicas en economía entre consumo y ahorro e inversión, y entre consumo y producción, pareciera que la ley no se aplica ni al ahorro, ni a las operaciones que integran el ciclo de producción.

Enseguida podría agregarse que el dinero -como objeto mediato de la contratación bancaria-y el crédito -como promesa de pago diferido que lo contiene- no constituyen adquisición del producto por el destinatario final, y por su propia naturaleza se integran al proceso de transformación que conduce al consumo, y no son en sí mismos consumo ${ }^{12}$.

Como respuesta contrastante podría oponerse que el Art. 36 ha extendido los efectos de la protección a "las relaciones de crédito en general" sin ceñirse estrictamente a la "relación de consumo" entendida con sentido restrictivo.

A su vez, podría replicarse que la extensión aludida es restrictiva y solo se aplica a "las operaciones de crédito para la adquisición de cosas o servicios", extremo que nos acerca a la objeción formal, a que antes hiciéramos referencia fundada en la intención fallida del legislador de extender la intervención a los "prestamos" y las restricciones implícitas que surgen del propio

Art. 36, cuando v.g se refiere "al precio de contado" - el que obviamente no aparece cuando el crédito no está especialmente referido a la adquisición de un bien o servicio determinado - y a la recomendación dada al BCRA para que disponga las medidas conducentes para la aplicación de la ley.

Sí, no obstante las objeciones, admitiéramos que la extensión alcanza a los créditos bancarios deberíamos intentar un ejercicio dialéctico para superar la limitación explícita que supone admitir la tutela solo cuando la operación financiera esté destinada a "la adquisición de cosas o servicios", y aún de lograrlo no alcanzaríamos otros supuestos del financiamiento bancario, ni en ningún caso la intervención podría extenderse a la otra expresión de la actividad: el ahorro, en cualquiera de sus manifestaciones.

Sin embargo entendemos posible justificar la extensión de la tutela a las operaciones bancarias atendiendo a "la causa" del negocio jurídico que pretende ejecutar el cliente con el bien adquirido a la entidad financiera; éste análisis, que no es extraño a la ley - desde que ella misma indaga sobre el destino del bien o servicio (Cfe. $2^{o}$ párrafo del Art. $\left.2^{\circ}\right)$ - , permite señalar que las operaciones de crédito, donde el objeto mediato es el dinero, no suponen siempre y necesariamente su incorporación a un ciclo productivo cuyo resultado interesa o vaya a favorecer de modo directo, ó aún a perjudicar, al cliente tomador del crédito.

Es cierto que, como se afirma, el dinero por su naturaleza está destinado a

12. Wald,A. El Dercho del Consumidor y sus Repercusiones en Relación con las Instituciones Financieras - Pag. 572. 
incorporarse a sucesivos procesos productivos, pero no lo es menos que la ley parece excluir de la tutela solo aquellas operaciones concluidas por quien incorpora específicamente los bienes primarios para alcanzar un resultado; no creemos en cam bio que tal exclusión proceda cuando el di nero se incorpora a la producción por obra de un tercero receptor del dinero, habién dose agotado para el consumidor - cliente bancario - la disponibilidad con la entrega y la obtención de algún otro recurso que lo sustituya, sea un bien o un servicio; para este el acto de disposición del dinero es una acto de consumo y como tal está alcanzado por la ley de protección al consumidor.

Aún si el crédito fuese destinado al ahorro, respecto de la relación habida entre cliente y entidad financiera, constituye desde al perspectiva de aquel un consumo dado que con su percepción ha consumido el crédito otorgado por el banco.

Si luego orientamos el análisis hacia los elementos objetivos de la relación de consumo podremos ratificar el criterio de inclusión del consumidor bancario bajo la órbita de la Ley 24.240. De acuerdo al Art. $1^{\circ}$ de esa norma quedan sujetas a sus dis posiciones la adquisición o locación de cosas muebles; la prestación de servicios; la adquisición de inmuebles nuevos destinados a vivienda, incluso los lotes de terreno adquiridos con el mismo fin, cuando la oferta sea publica y dirigida a personas determinadas.

Interesan sobre manera en el punto que nos ocupa los dos primeros supuestos enunciados.

Respecto de "la adquisición o locación de cosas muebles": realizando una interpretación extensiva, adecuada a la necesidad de ampliar la protección al consumidor, debe entenderse por "adquisición" - tal como surge desde una perspectiva económica - no sólo a la compraventa, sino también a la contratación de una obra, o a la celebración de un empréstito de consumo o mutuo"13.

Una reflexión similar cabe efectuarse respecto del término "locación", el que no cabe circunscribirlo al concepto jurídico del Art. 1493 del Código Civil, sino que debe aplicarse a cualquier titulo por el cual el consumidor tenga el derecho de usar o gozar de una cosa, se tipifique o no el contrato de locación de cosas regulado por los Arts. 1493 y ss. del Código Civil. Así por ejemplo, y sin necesidad de entrar a discutir su naturaleza jurídica, debe considerarse incluido al contrato de leasing; en efecto la Ley de Defensa del Consumidor alcanza a tal contrato cuando recae sobre cosas muebles o sobre inmuebles destinados a vivienda, siempre que el tomador resulte el destinatario final de los bienes, asimismo el leasing financiero configura una de las modalidades comprendidas dentro de las operaciones de crédito, por lo que debe sujetarse a las reglas del Art. $36^{14}$.

13. Wald, A. El Derecho del Consumidor y sus Repercusiones en Relación con las Instituciones Financieras - Pag. 572.

14. Zentner, D. El Contrto de Leasing: Su encuadramiento en el Estatuto del Consumidor - Ponenecia en Comisión de Contratos Modernos en VII Jornadas Bonaerenses de Derecho Civil, Comercial y Procesal, 1996.

Respecto de la "prestación de servicios" a diferencia de lo que ocurre con el concepto de "cosa", que se encuentra legalmente definido, lo que acota la labor interpretativa, no existe una noción legal de servicio o servicios. Por ello la expresión legal "prestación de servicios" permite ser interpretada ampliamente, lo que marca una situación más favorable a los intereses tutelados, en oposición a lo comentado en los párrafos anteriores.

Algunas definiciones de derecho comparado, pueden servir como guía para determinar el concepto de "servicio". El Código de Defensa del Consumidor de Brasil, Art. 3 o expresa que "Servicio es cualquier actividad prestada en el mercado de consumo mediante remuneración, inclusive las de naturaleza bancaria, financiera, de crédito y aseguradora, salvo las derivadas de las relaciones de carácter laboral". La propuesta de Directiva de la C.E.E. sobre Responsabilidad del Prestador de Servicios, define al servicio - Art. $2^{\circ}$ - como "cualquier prestación realizada a título profesional o de servicios público, de forma independiente, a titulo oneroso o no, que no tenga por objeto directo y exclusivo la producción de bienes o la transferencia de derechos reales o de propiedad intelectual ${ }^{15}$.

Así las objeciones señaladas respecto a la relaciòn de crédito no se proyectan en absoluto sobre la prestación de los servicios bancarios ya que, sin que pueda afirmarse de modo concluyente que se extiende a todos los que ejecuta la banca en virtud

de una disposición explícita, la prevención del Art. 19 no los excluye.

Es cierto, también que la ley no manda a aplicar sus normas a los servicios bancarios, como si lo hacen otros ordenamientos del derecho extranjero, pero la ausencia de tal extensión taxativa no parece conmover la aplicabilidad indicada ${ }^{16}$.

Por ello se puede concluir que la Ley de Protección al Consumidor es aplicable a las relaciones habidas entre bancos y clientes singulares, entendiendo por tales a aquellos que reúnan las condiciones subjetivas enunciadas en el Art. $1^{\circ}$, en su vinculación con las entidades financieras.

La aplicación de la ley se extiende a las relaciones de los servicios bancarios y del crédito bancario para el consumo y del crédito bancario en general aunque respecto de esta última relación la ley no sea todo lo concluyente que se hubiese deseado.

En efecto la Ley con la incorporación del Art. 36 disipa las objeciones substanciales que pueden formularse sobre la inclusión de las "operaciones de crédito" entre las relaciones tuteladas, aunque es innecesariamente restrictiva respecto de las relaciones de crèdito que protege ya que solo parece alcanzar aquellas destinadas a la adquisición de bienes de consumo y servicios.

Por ello - la exclusión implícita de otras relaciones de crédito exorbitantes de las destinadas a la adquisición de cosas o servicios -, la ausencia de previsión respecto de las operaciones de ahorro y la ausen-

15. Bergel y Paolantonio M. - Anotaciones sobre la Ley de Defensa del Consumidor. Pág. 500, Ed Revista El Derecho 155.

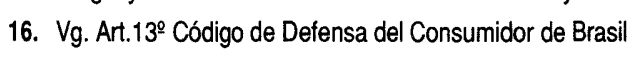


cia de una inclusión expresa de los servi cios bancarios, aconsejan introducir una re forma a la ley para incorporar todas las manifestaciones de tutela del crédito o bien tratar bajo un capitulo único todas las relaciones derivadas de la utilización de productos y servicios bancarios; o en su defecto alentar la promulgación de un estatuto es pecial para "la tutela del cliente bancario".

\section{Consecuencias de la \\ Aplicación de la Ley de \\ Protección al Cliente \\ Bancario:}

La aplicación de la Ley de Protección al Consumidor al cliente bancario que reúna las condiciones subjetivas de aquel y en las condiciones objetivas caracterizadas como relaciones de consumo de crédito y servicios financieros son sin duda significa tivos y al mismo tiempo recíprocamente positivas para entidades y usuarios.

Por lo pronto tales beneficios podemos agruparlos en dos grandes categorías: la primera, de índole estructural o sustancial y la segunda, de índole instrumental, ambas dentro claro está, de la enunciación genérica del Art. $1^{\circ}$ que define como objeto de la ley "la defensa de los consumidores o usuarios" y seguido por el principio del indubio pro consumidor del Art. 30.

a) Dentro de la primera de las cate gorías enunciadas - la de "índole estructu ral" - se encuentran aquellas previsiones legales destinadas a definir el contenido y las formas de las prestaciones: los modos

exigidos para la información que se suministra o debe suministrarse, las condiciones de la oferta y sus consecuencias, las modalidades de prestación de servicios, los requisitos exigidos en las operaciones de crédito, la interpretación e ineficacia de las cláusulas contractuales abusivas y finalmente la extensión de la responsabilidad por daños.

En efecto, relativo a la etapa formativa de las relaciones jurídicas el Art. $4^{\mathrm{Q}}$ señala en lo pertinente que quienes produzcan, distribuyan o comercialicen $\mathrm{CO}$ sas o presten servicios, deben suministrar a los consumidores o usuarios, en forma cierta y objetiva, información veraz, detallada, eficaz y suficiente sobre las características esenciales de los mismos.

En cuanto a la publicidad, cuya innegable orientación inductiva, informativa y formativa de la voluntad contractual se encuentra ya fuera de discusión, se prevé que las precisiones allí formuladas, como de igual modo sucede con aquellas contenidos en anuncios, prospectos, circulares u otros medios de difusión, obligan al oferente y se tienen por incluidas en el contrato con el consumidor (Cfe. Art. $8^{\circ}$ ), por lo demás hubiese resultado adecuado incorporar a la presunción integradora a la documentación precontractual.

En este aspecto el Banco Central de la República Argentina ya se había adelantado en buena medida con la Circular de Creación y Expansión de las Entidades Financieras ${ }^{17}$ luego derogada ${ }^{18}$.

17. Circular CREFI 1 BCRA (Com.A 46 del 20.06.81) en el Cap. IX Pto. 1 - Uso de Terminología Financiera - Pto.2 Institucional - Pro.3 de la Tasa de Interés de las Operaciones Financieras (ADLA XLI -C Pag.3246 y 516.

18. Circular CREFI 2 BCRA - Comunicación A 2241 del 02.09.94.
Allí por ejemplo se señalaba que "queda prohibido a toda persona física o de existencia ideal no comprendida en el régimen de la Ley 21.526, utilizar como medio para lograr -directa o indirectamente- recursos monetarios del público, las palabras "depósito", "ahorro", "cuenta corriente", "cheque" y sus derivados para distinguir o designar esos fondos y/o los documentos empleados para efectuar libranzas sobre ellos, se consideran medios aptos para esa finalidad, toda clase de avisos y documentos destinados al público o a personas indeterminadas, o mediante corredores de puerta a puerta o circulares generales a personas determinadas".

La citada disposición agregaba que "en la publicidad -en particular en aquella que se realiza a través de los medios masivos de comunicación - deben mantenerse las características tradicionales de sobriedad y discreción que, en general, ha man tenido la propaganda de las entidades financieras. Por consiguiente, corresponde eliminar referencias inexactas, equivocas o ambiguas que induzcan a duda o error a público, como también aquellas que puedan dar lugar a interpretaciones contradic torias con relación a las normas, políticas u orientaciones impartidas por el Banco Central".

Por último se advertía que "en toda publicidad, cualquiera fuere el medio de difusión que se utilice, destinada a promocionar la captaciòn de fondos o a ofrecer líneas de crédito debe informarse la tasa anual efectiva, equivalente al cálculo de los intereses en forma vencida sobre saldos, en tanto por ciento; queda prohibido efectuar publicidad referente a la captación de fon- dos, bajo cualquier modalidad operativa, ofreciendo el pago de intereses por adelantado".

Por lo demás una información adecuada contribuiría enormemente a disipar los riesgos tangibles de la adhesión a negocios cuyo objeto no aparece enunciado suficientemente, o aún siéndolo en origen, por efecto de las prerrogativas resevadas por la banca concluyen desnaturalizándose; vaya como ejemplo la posibilidad de suprimir servicios que integran las llamadas "cuentas únicas de servicios múltiples" o la restricción a la amortización anticiapada en los préstamos.

Ya introducidos en los términos del consentimiento el Art. $7^{\circ}$ de la ley 24.240 señala que la oferta dirigida a consumidores potenciales indeterminados, obliga a quien la emite durante el tiempo en que se realice, debiendo contener la fecha precisa de comienzo y finalización, así como también sus modalidades, condiciones y limitaciones.

Coherentemente se establece que la revocación de la oferta hecha pública es eficaz una vez que haya sido difundida por medios similares a los empleados para hacerlos conocer $\left(2^{\circ}\right.$ párrafo Art. $\left.7^{\circ}\right)$.

Cuando el objeto de la prestación se refiere a servicios, el Art. 19 prevé que quien los preste -cualquiera sea su naturaleza- está obligado a respetar los términos, plazos, condiciones, modalidades, reservas y demás circunstancias conforme a los cuales hayan sido ofrecidos, publicitados o convenidos.

Si la prestación está referida a la dación de crédito para la adquisición de 
cosas o servicios debe consignarse bajo pena de nulidad: el precio de contado, el saldo de deuda, el total de los intereses a pagar, la tasa de interés efectiva anual, la forma de amortización de los intereses, los gastos si los hubiere, cantidad de pagos a realizar y su periodicidad, gastos extras o adicionales si los hubiera y monto total financiado a pagar (Cfe. Art. 36).

Sobre la vaguedad del título que pre cede a esta disposición, cuanto a la restric ción que supone la referencia al "consumo" y el "precio de contado" ya hemos señalado por un lado la necesidad de alentar una interpretación amplia que alcance a todas las operaciones de crédito incluyendo naturalmente al bancario, y por otro las ventajas que derivarían de una adecuación legislativa para eludir las disquisiciones doctrinarias restrictivas sobre los alcances reales de la tutela.

Luego la enunciación del Art. 36 no alcanza a los créditos con utilización reiterada (tipo revolving) como se verifica en las tarjetas de crédito, la apertura de crédito y la autorización para girar en descubierto en la cuenta corriente.

En punto a la determinación, difusión y conocimiento exacto del precio del bien o servicio tambièn se ocupó puntualmente el BCRA ${ }^{19}$ al establecer que en todas las operaciones, cualquiera sea su instrumentación en los contratos, recibos, notas de débito $u$ otros documentos de relación con los clientes, donde se explicitan tasas o importes de intereses, se haga expresa menciòn de la tasa de interés, o de

descuento anual contractualmente aplicada y de la tasa de interés efectiva mensual o anual-según corresponda a operaciones en pesos o moneda extranjera, respectivamente- equivalente al cálculo de los intereses en forma vencida sobre saldos, se dejará constancia del "Costo Financiero Total" para lo cuảl se considerará al efecto los distintos cargos asociados a la operación, cualquiera sea su concepto según lo previsto en el párrafo siguiente.

El párrafo en cuestión señala que en toda publicidad impresa, con prescinden cia del medio de difusión que se utilice, relativa a operaciones de crédito, cualquiera sea su instrumentación, deberá incluirse información sobre la mayor y la menor de las tasas de interés que se ofrezcan a los clientes y la tasa activa promedio ponderada por operaciones concertadas en el mes anterior al que corresponda. Asimismo, deberá observarse, con carácter obligatorio, la exhibición de tal información en las pizarras colocadas en locales de atención al público. Cuando se trata de operaciones en pesos y en títulos valores públicos nacionales emitidos en esa moneda, se comunicaran las tasas nominal anual y efectiva mensual equivalente, esta última al cálculo de los intereses en forma vencida sobre saldos, en tanto por ciento. En el caso de operaciones en moneda extranjera, y en títulos valores públicos nacionales nominados en esa especie se informarán las tasas nominal y efectiva anual, equivalente, esta última, al cálculo de los intereses en forma vencida sobre saldos, en tanto por ciento. Cuando por cualquier medio - incluyendo radial o televisivo- se publicite el ofrecimiento de créditos en operatorias especificas (por ej. créditos hipotecarios para vivienda) deberá informarse las tasas nominal y efectiva anual en operaciones en pesos como en moneda extranjera ${ }^{20}$.

En estos casos, la tasa efectiva deberá reflejar el "Costo Financiero Total" de las operación considerando el efecto de los distintos cargos asociados a la operación además de la tasa de interés- cualquiera sea el concepto (por ej.; comisiones por la prestación de servicios, reintegro de gastos ad mitido, gastos de escrituración e inscripción de gravámenes, comisión por intermediaciòn inmobiliaria en el importe que exceda el normal de plaza, integración de acciones en el caso de entidades de naturaleza cooperativa, etc.), constituyéndose tal enunciación en un elemento de intereses relevante en la toma de créditos, en especial en aquellos de largo plazo v.g. los hipotecarios, desde que allí la rescición no aparece como un recurso eficaz para evadirse de la carga exesiva, como de hecho podría acaecer en los servicios de tarjeta de crédito.

Finalmente la influencia positiva de la ley de tutela en la estructura negocial se verifica en el capítulo IX cuando se ocupa de "los términos abusivos y las cláusulas ineficaces".

Relativo a la interpretación se señala que sin perjuicio de la validez del contrato, se tendrán por no convenidas:

- Las cláusulas que desnaturalicen las obligaciones o limiten la responsabilidad por daños; (v.g. limitación en el resarcimiento en el supuesto de robo en la caja de seguridad)

- Las cláusulas que importen renuncia o restricción de los derechos del consumidor o amplíen los derechos de la otra parte; (v.g. imposibilidad de observar resúmenes, irrevocabilidad de mandato)

- Las cláusulas que contengan cualquier precepto que imponga la inversión de la carga de la prueba en perjuicio del consumidor (v.g. aquellos donde se consigna que el origen del daño se presume que proviene del caso fortuito o fuerza mayor)

- La interpretación del contrato se hará en el sentido mas favorable para el consumidor. Cuando existan dudas sobre los alcances de su obligación, se estará a la que sea menos gravosa.

En caso que el oferente viole el deber de buena fè en la etapa previa a la conclusión del contrato o en su celebración o transgreda el deber de información o la legislación de defensa de la competencia o de lealtad comercial, el consumidor tendrá derecho a demandar la nulidad del contrato o la de una o más cláusulas. Cuando el Juez declare la nulidad parcial simultáneamente integrará el contrato, si ello fuera necesario (Art. 37). En el punto "la información debida" cabe entenderla en el sentido más vasto v.g: sobre el contenido contractual, sobre el estado financiero de la entidad, sobre las condiciones de la plaza financiera, y aún sobre las viscisitudes de la ejecución del negocio. 
El ultimo aspecto sustancial que preveía la Ley de Protección del Consumidor era el referido a la responsabilidad por daños, con una minuciosa y extensa enunciación de legitimados pasivos respecto de los cuales se preveía una responsabilidad solidaria, sin embargo tal enunciación fue excluida por imperio del veto del Poder Ejecutivo.

Antes de ello el Art. 40 preveía que: "Si el daño al consumidor resulta del vicio o defecto de la cosa o de la prestación del servicio responderá el productor, el fabricante, el importador, el distribuidor, el proveedor, el vendedor y quien haya puesto su marca en la cosa o servicio. El transportista responderá por los daños ocasionados a la cosa con motivo o en ocasión del servicio".

Sólo por citar un ejemplo piénsese en la ventaja que se proyectaría para los usuarios respecto de los emisores de sistemas de tarjetas de crédito o cajeros automáticos frente a supuestos de incumplimiento en la prestación, obviando las pesquisas relativas a identificar al causante del daño en un circuito administrativo que al cliente le es por completo extraño e inescrutable.

a) La protección también se vuelve tangible para el usuario bancario en el segundo de los aspectos que enunciáramos - el instrumental -: v.g. en la necesidad de someter a contralor administrativo los contratos tipos; la determinación de un procedimiento administrativo especifico para supuesto de presuntas infracciones a las disposiciones de la ley; la aplicación del proceso màs abreviado que rija en la jurisdicción del Tribunal ordinario competente: los efectos expansivos de la cosa juzgada; y la aplicaciòn de los legitimados para accionar

El Art. 38 prevé que: "La autoridad de aplicación vigilará que los contratos de adhesión o similares, no contengan cláusulas de las previstas en el artículo anterior. La misma atribución se ejercerá respecto de las cláusulas uniformes, generales o estandarizadas de los contratos hechos en formularios, reproducidos en serie y en general, cuando dichas cláusulas hayan sido redactadas unilateralmente por el proveedor de la cosa o servicio, sin que la contraparte tuviere posibilidades de discutir su contenido".

Por su parte el Art. 45 señala que en lo sustancial la autoridad nacional de aplicación iniciará actuaciones administrativas en caso de presuntas infracciones a las disposiciones de la presente ley, sus normas reglamentarias y resoluciones que en consecuencia se dicten, de oficio o por denuncia de quien invocare un interés particular o actuare en defensa del interés general de los consumidores.

A su tiempo el Art. 47 pevè las sanciones a los supuestos en que se verifique la existencia de infracciones a la ley tales como: apercibimiento, multas, perdida de beneficios, clausuras.

Estas previsiones sin embargo en la materia que nos ocupa -la actividad bancaria- enfrenta un obstaculo severo, en tanto y en cuanto la autoridad de aplicación de la ley es según los términos del Art. 41 la Secretaria de Industria y Comercio para la aplicación de la ley en el ámbito nacional, quien resulta a todas luces incompetente para intervenir en la actividad financiera.

Admitir su intervención supondría una invasión de la competencia propia del BCRA.

El vacío apuntado estaba sin duda en la conciencia del legislador quien en el Art. 36 previó que el BCRA adoptará las medidas conducentes para que las entidades sometidas a su jurisdicción cumplan, en las operaciones de crédito para consumo, con lo indicado en esta ley.

La referencia a una de las manifestaciones de la actividad bancaria -el crédito para el consumo- no fue feliz, ya que podría dar pábulo para sostener la inaplicabilidad de la ley a otras alternativas negociales bancarias, como ya se apuntara.

Lo relativo a la aplicaciòn del proceso judicial más abreviado -el mecanismo(Cfe. Art. 53 de la ley del consumidor) cuanto a los legitimados activos para accionar (Cfe. Art. 52 párrafo) y los efectos de la sentencia, (Cfe. Art. 54), no están en modo alguno ensombrecidos por la incompetencia o la ausencia normativa de una autoridad de aplicación para la actividad financiera, desde que se trata de soluciones extrañas al procedimiento administrativo.

En efecto el Art. 53 prevé que se aplicarán las normas del proceso de conocimiento más abreviado que rijan en la jurisdicción del tribunal ordinario competente, en obvia alusión al juicio sumarísimo.

Quienes ejerzan las acciones previstas en esta ley representando un derecho o interés individual podrán acreditar mandato mediante simple acta poder en los términos que establezca la reglamentación.

En cuanto a la amplitud de los legitimados procesales activos el Art. 52 señala que sin perjuicio de lo expuesto, el consumidor y usuario podrán iniciar acciones judiciales cuando sus intereses resulten afectados o amenazados.

La acción corresponderá al consumidor o usuario, a las asociaciones de consumidores constituidas como personas jurídicas, a la autoridad de aplicación nacional o local y al ministerio público. E ministerio público cuando no intervenga en el proceso como parte, actuará obligatoriamente como fiscal de la ley. Las asociaciones de consumidores estarán habilitadas como litisconsorte de cualquiera de las partes.

En caso de desistimiento o abandono de la acción de las referidas asociaciones legitimadas, la titularidad activa será asumida por el ministerio público.

La sentencia dictada en un proceso no promovido por el consumidor o usuario, solo tendrá autoridad de cosa juzgada para el demandado, cuando la acción promovida en los tèrminos establecidos en el segundo párrafo del Art. 52 sea admitida y la cuestión afecte un interés general.

Cuando la sentencia acogiere la pretensión, la apelación será concedida al sólo efecto devolutivo.

En este punto conviene recordar que el Art. 54 admitía la posibilidad de que un proceso promovido en interés general derivara en una sentencia con efectos para otros posibles demandados, extremo que fue ve- 
tado considerando que ello afectaría la defensa en juicio y la igualdad ante la ley, y pretendiendo evitar una proliferación indebida de causas judiciales; fundamentos juzgados luego críticamente porque el efecto seria justamente el contrario, como lo ha puesto de relieve la doctrina nacional y extranjera.

$\mathrm{Si}$ un proceso se refiere a una cuestión que es exactamente igual a la que afecta a un grupo de personas, no tiene mucho sentido obligar a todas a entablar el mismo proceso, sabiendo que se lo va a resolver del mismo modo ${ }^{21}$.

Como sea, y aún señalando críticamente el menoscabo severo que ha sufrido la Ley 24.240, los beneficios de extender la aplicación de la ley de tutela de consumidor a las relaciones habidas entre entidades financieras y público usuario que reúna las condiciones subjetivas del primer párrafo del Art. 1으, son notorias, como de igual modo lo son las dificultades de aplicar algunas de sus previsiones a ciertas operaciones de la actividad y de igual forma aplicar determinadas soluciones a las cuestiones conflictivas que se susciten; ambos factores imponen mejorar la ley de protección para alcanzar de modo pleno al cliente bancario o bien debe alentarse un estatuto tuitivo especifico.

\section{Conclusión:}

Tal como se intentará evidenciar en los párrafos precedentes el estatuto que tutela genéricamente al consumidor, si bien aplicable según nuestro criterio al cliente

bancario, ofrece flancos débiles que permiten formular reparos sobre su eficacia, su extensión y su operatividad respecto de las mas trascendentes relaciones negociales que cobran vida dentro del ámbito de la actividad, en particular respecto del ahorro y crédito sin determinación del destino.

De modo tal que aún adscribiendo a la iniciativa enunciada de aplicar el beneficio de la tutela al cliente bancario, en la práctica tropezaremos con severas dificultades: la exclusión de algunas operaciones, el vacío legal respecto de las prerrogativas de la administración, la inaplicabilidad de buena cantidad de reglas, y en fin el desconcierto por la posibilidad de normas superpuestas, con grave riesgo que en la confusión queden aspectos relevantes ignorados, cuando no el conflicto entre las distintas disposiciones normativas.

Es que la importancia económica y social de la actividad bancaria, como su dinámica contienen presupuestos de mayor complejidad que no siempre pueden estar alcanzados por los principios generales, sean los de la contratación o aún de los estatutos generales de protección al usuario.

Sólo por citar algunos supuestos de especificidad que requieren una especial atención podemos recordar los referentes a la terminología financiera, a la publicidad, a las tasas de interés, entre otros supuestos, respecto de algunos de los cuales se ocupó a su tiempo el BCRA como tuvimos oportunidad de señalar.

De allí que en el derecho comparado se ha avanzado significativamente en la ela-

21. Benélbaz, H. y Coll, O.- Sistema Bancario Moderno, Depalma ED 1994, T II, Pág.528, 536.

boración del estatuto del cliente bancario o, para decirlo con más propiedad, del consumidor de crédito.

En el intento, el crédito al consumo se define v.g. como la concesión, en el ejercicio de una actividad comercial o profesional, de crédito bajo la forma de diferimiento de pago, de financiación o de otra análoga facilidad financiera a favor de una persona física que la toma para objetos extraños a su actividad empresaria o profesional ejercida eventualmente ${ }^{22}$.

Es cierto que la formula evidencia una notable amplitud, ya que extiende la tutela a supuestos donde el crédito al consumo es suministrado por bancos u otros intermediarios financieros y aún por los sujetos autorizados a la venta de bienes y servicios.

Frente a ese cuadro no está de mas señalar que el estatuto del consumidor bancario se ha mostrado suficientemente idóneo para neutralizar los riesgos de la generalización que se desprende de la ley del consumidor

Sólo para citar un beneficio concreto los estatutos de protección del consumidor de crédito establecen la obligatoriedad de informar la "tasa anual efectiva global" comprensiva de los intereses, y de todos los costos que deben soportarse para utilizar el crédito para dar certeza al consumidor sobre el precio de la financiación y poder comparar las distintas ofertas de créditos al consumo.

Tal enunciación descripta como la disciplina de la "tasa global" confiere a las operaciones de crédito al consumo una transparencia mayor respecto de aquellas otras operaciones no financieras y bancarias, para las cuales la indicación del costo global no siempre es objeto de publicidad ni de necesaria especificación en el reglamento contractual ${ }^{23}$.

Otro ejemplo de prevención relevante nos lo ofrece las prerrogativas concedidas al prestatario dado el incumplimiento del proveedor del bien o servicio.

Una adecuada prevención legal relativa a la tutela del cliente en las relaciones bancarias permitiría incluir disposiciones relativas a la forma de los contratos, su contenido, la transparencia, la paridad de tratamiento, los margenes de garantía, entre otros.

Por el contrario la falta de una tutela especifica del cliente bancario provoca la exclusión de los segmentos de consumo económicamente más significativos.

Luego la incorporación de reglas comunes para el ejercicio de la actividad bancaria frente a la clientela proyecta reglas de juego idénticas para todos los agentes financieros, incrementa la competencia y facilita el control de la actividad.

22. Texto Uniforme Bancario Italiano, Art. 121.

23. Pedretti, II Crédito al Consumo Nella Nuova Legge Bancaria, en Disciplina del Commercio № 2, 1994, Pág.323. 